\title{
A POSSIBILIDADE DE UMA "ÉTICA QUÂNTICA" A PARTIR DO PENSAMENTO DE AMIT GosWAMI
}

\author{
[The POSSIBILITY OF A "QUANTUM ETHICS" FROM THE THOUGHT OF AMIT GoswAmi]
}

\author{
José Francisco de Assis Dias * \\ Universidade do Oeste do Paraná, Brasil \\ Ronaldo de Oliveira ** \\ Universidade do Oeste do Paraná, Brasil
}

Resumo: Esta pesquisa tem como tema a filosofia idealista monista de Amit Goswami que postula a Consciência Quântica como princípio unificador e mediador de toda a realidade em suas diversas facetas, manifestadas ou em potencial. Pretende-se responder ao problema sobre a possibilidade de uma ética quântica a partir do pensamento de Amit Goswami. Para tanto, apresenta-se a relação epistemológica entre "criatividade quântica e ética quântica"; depois, a "responsabilidade e ética quântica"; sem negligenciar os "critérios universais de uma ética quântica"; por fim, a relação entre "ética quântica e propósito". Esta pesquisa justifica-se pelo fato de a física quântica ser fundamento teórico para muitas invenções tecnológicas e ainda não existirem muitos estudos filosóficos que demonstram as implicações éticas desta ciência, tecnicamente bem-sucedida. A metodologia empregada foi de análise crítica das principais obras de Amit Goswami, sendo O Universo Autoconsciente (2003) a principal fonte por oferecer os elementos teóricos básicos para compreensão da temática pesquisada, pois nas demais obras o autor explora os conceitos fundamentais nela apresentados. Espera-se evidenciar que ao expandir consciência de uma pessoa, ela possa fazer escolhas com originalidade a partir de um nível inviolado, que é a consciência quântica, tornando-se criativa e responsável; o processo de descoberta da autoconsciência como
ABSTRACT: This research has as its theme the idealistic monistic philosophy of Amit Goswami that postulates Quantum Consciousness as a unifying principle and mediator of all reality in its manifold, manifested or potential. It is intended to answer the question about the possibility of a quantum ethics from the thought of Amit Goswami. For that, the epistemological relationship between "quantum creativity and quantum ethics" is presented; then "responsibility and quantum ethics"; without neglecting the "universal criteria of a quantum ethics"; finally, the relation between "quantum ethics and purpose". This research is justified by the fact that quantum physics is the theoretical basis for many technological inventions, and there are still not many philosophical studies that demonstrate the ethical implications of this technically successful science. The methodology used was a critical analysis of the main works of Amit Goswami, with $O$ Universo Autoconsciente (2003) being the main source for offering the basic theoretical elements for understanding the researched topic, since in other works the author explores the fundamental concepts presented in it. It is hoped to show that by expanding a person's awareness, he can make choices with originality from a inviolate level, which is the quantum consciousness, becoming creative and responsible; the process of discovering selfconsciousness as a self-referential unfolding of

* Doutor em Filosofia pela Pontifícia Universidade Urbaniana, Cidade do Vaticano, Roma, Itália. Professor da Universidade do Oeste do Praná - UNIOESTE, Campus Toledo-PR. Coordenador do curso de Licenciatura em Filosofia.E-mail:prof.dias.br@gmail.com. ** Mestre em Filosofia pela Universidade Estadual do Oeste do Paraná. Professor de Filosofia da Secretaria de Estado de Educação do Paraná.E-mail: ronaldodeoliver@hotmail.com 
desdobramento autorreferencial da Consciência, se aplicado à educação, tem impacto direto nas relações entre as pessoas visto que podem se descobrir como cocriadores da realidade porque se percebem como observadores conscientes com autorreferência, como sujeitos que escolhendo com criatividade podem transformar o mundo enquanto se transformam.

Palavras-chaVe: Ética quântica; Amit Goswami; Consciência quântica; Responsabilidade ética
Consciousness, if applied to education, has a direct impact on the relationships between people, since they can be discovered as cocreators of reality because they perceive themselves as conscious observers with selfreference, Creativity can transform the world as they transform.

KEYwords: Quantum ethics; Amit Goswami; Quantum consciousness; Ethical responsibility

\section{INTRODUÇÃo}

A presente pesquisa abordará o tema da ética quântica na filosofia idealista A monista de Amit Goswami que postulou a Consciência Quântica como princípio unificador e mediador de toda a realidade em suas diversas facetas, manifestadas ou em potencial.

Pretende-se dar uma resposta filosófica ao problema sobre a possibilidade de uma ética quântica a partir do pensamento de Amit Goswami. Para tanto, apresentar-seá a relação epistemológica entre "criatividade quântica e ética quântica"; "responsabilidade e ética quântica"; os "critérios universais de uma ética quântica"; por fim, a relação entre "ética quântica e propósito".

Será apresentada uma Ética Quântica com os critérios universais decorrentes da íntima relação entre consciência quântica e ética da responsabilidade diante do mundo e das pessoas a partir da analogia entre Goswami e Plotino. Partindo da concepção de homem como um ser animado por uma alma particular, Plotino desenvolveu sua teoria ética alinhada com a estrutura espiritual das hipóstases. $\mathrm{O}$ homem, em sua perfeição ética, deve empreender o retorno à sua origem, ao mundo espiritual por meio da renúncia ao comércio e à identificação com o mundo material ou mundo sensível.

Constataremos em Plotino que os caminhos pelos quais o homem se eleva ao mundo espiritual são: as virtudes, a erótica e a dialética. Pela própria força interna, o homem ascende à dimensão cada vez mais elevada, isto é, ao mundo espiritual. Neste aspecto, constatou-se que o homem deve fugir da relação com o mundo sensível à medida que experienciar, por meio do êxtase, a iluminação.

A Ética Quântica, na perspectiva de Goswami, parte da concepção de homem como o self quântico que é resultado da hierarquia entrelaçada, provocada pela causação descendente, na qual a consciência quântica se identifica com o sujeito (self) ao observar o objeto. O homem é uma individuação da Consciência Quântica manifestada que se identifica com o sujeito, com o self. A percepção de que o ser humano é separado da consciência quântica, surge por meio das chamadas assinaturas quânticas e pelos condicionamentos retroalimentados que formam o "ego".

Será elucidado que uma característica fundamental da ética quântica é a criatividade. Esta característica está em consonância com a visão quântica, cujos princípios são: princípios da incerteza, da complementaridade, da descontinuidade, da inseparabilidade, do observador consciente e da não-localidade.

Fazendo a relação da criatividade ética com os elencados princípios da teoria quântica, destacaremos que do princípio da incerteza se pode extrair o entendimento de que o desejo de domínio sobre os indivíduos, ou até mesmo sobre o ambiente à volta desses, não se justifica. Assim, a criatividade é compatível com o princípio da incerteza. A criatividade ética se adequa ao princípio da complementaridade. O self quântico é complementado pelo self condicionado. O self quântico oferece a intuição e o ego, 
alicerçado nas habilidades aprendidas e armazenadas no repertório "pessoal", se encarrega de dar "concretude" à intuição ou insight. Goswami, nesse aspecto, afirma que a criatividade interior não se torna completa até que o "produto", a transformação do self, seja "concluída e comunicada para que os outros vejam" (GOSWAMI, 2003, p. 307).

A criatividade ética não é um sistema rígido, inflexível, de comportamento ou até mesmo de regras, por isso é compatível com o princípio da descontinuidade, da inseparabilidade e com os demais princípios da teoria quântica. A criatividade ética, como característica essencial da ética quântica, revela uma perspectiva de plena abertura do observador ao momento presente, sempre à espreita do movimento e da expansão da consciência. A criatividade é o domínio da liberdade. Desta forma, a criatividade quântica é o método para solucionar dilemas e paradoxos que afligem as relações humanas. E por ser criativo e livre, o ser humano também é responsável. A responsabilidade se impõe como exigência pelo princípio da inseparabilidade.

A ética quântica, segundo Goswami tem de refletir sobre a busca da felicidade pelo homem (GOSWAMI, 2003, p. 298) e, nessa perspectiva, tem de orientar para um movimento na direção da totalidade, para a integração do self quântico e self-ego (GOSWAMI, 2003, p. 298). A ética quântica tem de explorar o "bem" entendido como a vivência do indivíduo a partir da modalidade quântica enquanto se está no mundo. A partir disto, a ética quântica tem de postular como princípio geral a "preservação e a facilitação do acesso, ao nosso e do outro, à modalidade quântica" no nível intuitivo do ser, que inclua a liberdade, a criatividade e a responsabilidade (GOSWAMI, 2003, p. 306).

Ainda serão expostos os estágios que se interpenetram enquanto se explora a ética quântica. Goswami propõe três estágios que consistem em: agir sem apego aos frutos da ação; agir a serviço dos demais; agir alinhado à vontade da modalidade quântica.

Espera-se evidenciar que ao expandir consciência de uma pessoa, ela possa fazer escolhas com originalidade a partir de um nível inviolado, que é a consciência quântica, tornando-se criativa e responsável; o processo de descoberta da autoconsciência como desdobramento autorreferencial da Consciência, se aplicado à educação, tem impacto direto nas relações entre as pessoas visto que podem se descobrir como co-criadores da realidade porque se percebem como observadores conscientes com autorreferência, como sujeitos que escolhendo com criatividade podem transformar o mundo enquanto se transformam.

\section{CRIATIVIDADE QUÂNTICA E ÉTICA QUÂNTICA}

Para a ética quântica a criatividade é de fundamental importância porque busca integrar o self quântico e o ego, a unidade básica e o individual. A criatividade quântica busca explorar as ondas de possibilidade de maneira intencional e dinâmica em um processo em que a transformação interna se desdobra e se manifesta na exterioridade. A ética quântica alicerçada na criatividade quântica é "fundamentalmente proativa" (GOSWAMI, 2003, p. 297). A metodologia para explorar a criatividade quântica possui quatro etapas. Cada etapa cria mais ondas de possibilidade. Cada onda de possibilidade somada com outra onda de possibilidade gera mais ondas de possibilidade.

A lógica é a mesma do experimento da dupla fenda, no qual uma onda ao encontrar com outra onda provoca um padrão de interferência que, em alguns pontos, é reforçado e em outros pontos esse padrão de interferência é anulado. Cada onda de possibilidade, ao interferir com outra onda de possibilidade, gera mais ondas de possibilidades, ora se reforçando em alguns pontos, ora se anulando em outros. Destacando: ondas de possibilidade mais ondas de possibilidades geram mais ondas de 
possibilidade. Isto vai ao infinito. E este processo de gerar mais onda de possibilidade ou de expandir a onda de possibilidade de um evento é chamado por Goswami de Causação Ascendente, como já foi analisado acima.

O processo criativo é deliberado pelo sujeito consciente. Quando o indivíduo se abre à vivência de novas experiências, o processo criativo é desencadeado e segue um fluxo que é o da Consciência Una e Cósmica. Ao indivíduo humano cabe potencializar a manifestação. Para que algo se manifeste no espaço tridimensional, tem de haver a potência latente, real. As etapas do processo criativo são: preparação, incubação, revelação/insight e manifestação.

O primeiro estágio é o da preparação: o sujeito estuda o que existe sobre algo, aprende o que existe sobre algo, ou seja, deve "aprender o que já se sabe" sobre algum tema ou propósito que decidiu explorar. A criatividade quântica aplicada à ética quântica começa a partir do momento em que se questiona as informações obtidas explícita e implicitamente, questiona-se o problema "concreto" e se abre às possíveis soluções ainda não experimentadas (GOSWAMI, 2015, p. 149 CPS).

O segundo estágio do processo criativo é o da incubação: depois de explorar um tema, um propósito, um problema "concreto", um assunto ou algo de interesse, o indivíduo deve se acalmar, deve entrar no fenômeno de incubar. Esta etapa é para o inconsciente processar as ondas de possibilidade gerando mais ondas de possibilidade.

Nestes dois estágios iniciais se verifica o que Goswami classifica metodologicamente como do-be-do-be-do (fazer-ser-fazer-ser-fazer). Quando se quer manifestar criativamente o sujeito faz algo, como estudar, coletar informações mais diversas, por exemplo. Depois deixa as informações aquietarem por um tempo (é o período do ser). Assim o ciclo do-be-do-be-do se repete ao longo de todo o processo criativo. A etapa seguinte é o da revelação. Esse fenômeno surge na consciência de maneira súbita e intuitiva. É um "salto quântico" que a Consciência opera no sujeito da experiência criativa.

É a intuição que revela num ato livre e genuíno a "grande ideia" criativa em resposta da intenção. Goswami afirma que é "importante o caráter intencional da criatividade - existe uma intuição da solução que se revelará bastante adequada. A intuição é intimada pelo self quântico como inspiração" (GOSWAMI, 2015, p. 152 CPS).

O último estágio é o da manifestação. Usando os recursos disponíveis, tais como a linguagem e a tecnologia, o sujeito começa a dar forma manifesta ao insight recebido ou revelado pelo self quântico. Sobre esse estágio, Goswami elucida que "o self em sua modalidade de ego tem de desenvolver a forma para a ideia criativa gerada no estágio três. Ele tem de sair e organizar os elementos da ideia e verificar que ela funciona" (GOSWAMI, 2015, p. 157 CPS). Há, na criatividade quântica, uma dialética entre self e "ego". A "nova ideia" ou "nova solução" precisa encontrar o "canal" de manifestação que é o ego com seu repertório aprendido, memorizado, ao longo da vida.

Duas destas etapas do processo criativo são processadas pelo self quântico, a saber, a incubação e a revelação. Goswami classifica estas duas etapas como processos quânticos (GOSWAMI, 2013, p. 66). Já a preparação e a manifestação são etapas ligadas às estruturas do ego clássico, condicionado. Desta forma "a criatividade é o encontro do ego com o eu quântico" (GOSWAMI, 2013, p. 66).

A ética quântica, que Goswami chama "Ética Idealista", propõe o questionamento da "adoção implícita de uma visão de cognitiva-behaviorista de nós mesmos - a ideia de que somos máquinas clássicas e, portanto, governadas pela genética e condicionamento ambiental" (GOSWAMI, 2003, p. 296). Pois se o ser humano for "máquina" que age somente conforme os "programas informacionais" implantados, não faz sentido a reflexão sobre valores, ética, responsabilidade, liberdade, criatividade fundamental que possam orientá-lo (GOSWAMI, 2003, p. 297).

Goswami, ao analisar experimento de Alain Aspect, afirma que ele "indica 
conclusivamente que nossa separatividade do mundo é ilusória" (GOSWAMI, 2003, p. 297). Com isto, justifica uma ética como "parte de um esquema universal de coisas" (GOSWAMI, 2003, p. 297). Na visão de mundo quântica se reconhece a fundamental importância dos valores éticos, dos preceitos morais, no entanto é necessário despi-los do dogmatismo, da "racionalização que prefere honrar a letra ao espírito da lei" (GOSWAMI, 2003, p. 296).

A ética quântica, calcada na compreensão das hierarquias entrelaçadas, reconhece que a separatividade ocorre por causa da identificação da consciência com o cérebro e seus circuitos de memórias mediante o colapso da função de onda. Quando um contexto antigo não possibilita novos significados para a expressão ou expressividade da consciência, requer que novos contextos e novos significados sejam criados. Na visão de mundo quântica, a criatividade é uma constante. A ética quântica deve incluir em sua estrutura formal a criatividade quântica como metodologia para solucionar dilemas e paradoxos que afligem as relações humanas. Dizendo de outra maneira, um comportamento ético fundado somente nos circuitos cerebrais já conhecidos e cristalizados se torna egóico, excludente, julgador. O comportamento ético fundado no self quântico é criativo e se manifesta à mente pela intuição estando de acordo com o movimento dinâmico da Consciência Quântica (GOSWAMMI, 2018, p. 112).

A ética quântica tem de "refletir a busca da felicidade" pelo homem, que consiste em solucionar conflitos internos de valores" (GOSWAMI, 2003, p. 298). A ética, nesta perspectiva, tem de orientar para um movimento na direção da totalidade, para a integração do self quântico e self-ego (GOSWAMI, 2003, p. 298).

Goswami entende que o segundo princípio da ética quântica consiste em admitir a "inseparabilidade entre ética e criatividade" (GOSWAMI, 2003, p. 298). Sendo assim, a ética quântica

não pode ser calcificada por sistemas de crenças ritualistas. Em vez disso, deve fluir expressivamente da prática da criatividade interna pelo ser humano. Evidentemente, essa ética terá que desmentir ocasionalmente crenças do realismo materialista (GOSWAMI, 2003, p. 298).

\section{Responsabilidade e ética quântica}

No experimento de Alain Aspect e de seus colaboradores, realizado em 1982, constatou-se que a mediação quântica de único objeto quântico afeta o seu parceiro correlacionado por polarização sem qualquer troca de sinais locais entre ambos, independentemente da distância (GOSWAMI, 2003, p. 149).

Admitindo a Consciência Quântica, como a base da realidade ou o domínio da potencialidade pura, nada escapa a ela. É necessário admitir que ela atua não só no nível micro do mundo, mas também no nível macro do mundo. Goswami enfatiza que "a física quântica força-nos a concluir que o domínio da potencialidade é, na verdade, a própria consciência" (GOSWAMI, 2018, p. 26).

Apoiado em experimento, é lícito dizer que a não localidade quântica, pode afetar o nível macro da experiência humana. Goswami afirma que "a comunicação sem sinal ocorre de fato, não só no mundo microscópico como também no mundo macro da matéria e da experiência humana" (GOSWAMI, 2018, p. 26). Um experimento, em especial, ilustra a interação não local entre dois cérebros correlacionados. Foi feito em 1994, pelo neurofisiologista Jacobo Grinberg Zylberbaum e colaboradores. O experimento começa selecionando dois indivíduos humanos que por um tempo meditam intencionalmente juntos. Na sequência, são separados e isolados em compartimentos com isolamento capaz de bloquear qualquer sinal eletromagnético chamados de "Gaiolas de Faraday". Em seguida, um dos sujeitos é submetido a uma série de sinais luminosos que estimulam o cérebro equipado com um aparelho de medição Eletroencefalograma (EEG) para detectar as ondas cerebrais provocadas pelos 
estímulos luminosos (GOSWAMI, 2005, p. 50-55). Espantosamente, no cérebro do sujeito não submetido aos estímulos luminosos o EEG capta uma atividade eletrofisiológica semelhante ao do cérebro diretamente estimulado. A explicação é a comunicação direta da não localidade quântica: "os dois cérebros-mentes agem como um sistema correlacionado não-localmente" (GOSWAMI, 2003, p. 165).

Há uma sutileza que deve ser esclarecida nesse experimento que é a questão da sincronicidade $^{2}$ do colapso quântico. Assim só se torna clara a correlação entre os dois cérebros-mentes quando são comparados os EEGs com seus registros (GOSWAMI, 2003 , p. 165). Os eventos da não localidade quântica acontece fundamentalmente no inconsciente, isso implica admitir que enquanto qualquer estímulo não é reconhecido com percepção presente ele é apenas uma onda de possibilidade na Consciência. Goswami (2005, p. 52) escreve que

deve-se admitir que, nessas experiências ${ }^{3}$, o sujeito correlacionado nãoestimulado não vivencia, na verdade, o estímulo experimentado pelo parceiro; provavelmente, para isso, será necessário outro salto na pureza de intenções. Contudo, é realmente notável que as ondas cerebrais de um sujeito possam ser comunicadas a outro sujeito sem transferências locais de sinais.

Neste excerto deve ser destacada a relevância da intenção nas relações interpessoais. A Consciência Quântica não-local não viola a vontade do sujeito, pois "a intenção consciente e a concordância dos dois sujeitos são cruciais para o sucesso de qualquer comunicação" não-local (GOSWAMI, 2005, p. 55). Para que a sincronicidade ocorra em nível não local tem de ter alguma disposição que dê abertura para a ação não local da Consciência. $\mathrm{O}$ ego fechado à criatividade não pode ser afetado pela unidade do self quântico. Sempre que houver o encontro livre e decidido por interesses subjetivos ou objetivos, há ali uma correlação que não necessariamente precisa ser presencialmente física. Após a correlação, o que um cérebro colapsar ou outro parceiro correlacionado está envolvido na equação pelo sincronismo da dinâmica do colapso de causação descendente da Consciência Quântica.

À medida que o indivíduo se envolver no processo de transformação e de integração dos selfs, a ética da responsabilidade pelo "mundo que se é" surge como dever $^{4}$, pois "códigos de éticas não são principalmente regras para comportamento externo, mas instruções para meditação interna" enquanto o indivíduo se comporta externamente (GOSWAMI, 2003, p. 303). Além disso, a Teoria Quântica preconiza que a Consciência Una é livre optadora, e quando se reconhece que é livre para escolher na modalidade quântica, isto gera, consequentemente, o senso de responsabilidade por aquilo que foi escolhido, como também pelas consequências advindas da escolha.

Sobre a relação entre liberdade e responsabilidade, Goswami (2003, p. 300) escreve que

tão logo compreendemos que temos o privilégio inerente de agir na modalidade quântica, com liberdade e criatividade, então todo o argumento em favor de aspectos subjetivos da ética assume o imediatismo da realidade. Reconhecer que somos livres em nossos atos implica admitir que somos responsáveis por eles.

Como a Consciência Quântica é Una, e a separação entre o "mim" e os "outros" é aparente, a responsabilidade é um princípio co-criado com a liberdade, pois "ferir os outros é ferir nosso self, e vice-versa" (GOSWAMI, 2003, p. 301). No entanto, há uma tendência de fuga da responsabilidade à medida que o indivíduo se conforma com os condicionamentos do ego. Goswami destaca que "embora tenhamos liberdade de opção na modalidade quântica, somos também seres classicamente condicionados [...]. Essa tendência para evitar opções estende-se à tendência para evitar a responsabilidade" (GOSWAMI, 2003, p. 302).

O bem na Ética quântica deve ser entendido como sendo a transformação da 
vivência do indivíduo a partir da modalidade quântica enquanto se está no mundo. A Ética e as leis morais são insinuações para que a pessoa conheça o seu self quântico por completo, aquele que se situa para além do ego (GOSWAMI, 2003, p 303-304). A Ética da responsabilidade envolve, ao mesmo tempo, a liberdade interior criativa (enquanto se comporta externamente) e a responsabilidade mediante o encontro transformador do self clássico com o self quântico. Goswami entende que ao maximizar o "acesso ao self quântico, à criatividade e ao livre-arbítrio", o indivíduo se torna comprometido com uma transformação da psiquê (GOSWAMI, 2003, p. 306-307).

\section{CRITÉRIOS UNIVERSAIS DE UMA ÉTICA QUÂNTICA}

Diante do que foi exposto, entende-se que a Consciência Quântica subjaz a todo e qualquer fenômeno, sendo físico ou não físico, como condição sine qua non. A manifestação da Consciência Quântica se dá por meio da escolha autorreferenciada, ou seja, mediante um cérebro no qual a Consciência possa se identificar. Um colapso da função de onda se dá, simultaneamente, em todos os mundos de possibilidades conforme a natureza da experiência material, sutil, mental e supramental. A Consciência Quântica tem, em si, todos os mundos de possibilidades e é ela que medeia as interações entre eles.

Sendo a consciência quântica a dimensão na qual há unidade original e que a experiência humana autorreferenciada acontece por causa do self que se identifica com o cérebro que observa o objeto, cabe destacar quais seriam os critérios que orientam a "ação boa". A ética quântica deve ser uma metodologia de exploração "do bem", entendido como a vivência do indivíduo a partir da modalidade quântica enquanto se está no mundo. Na filosofia de Plotino o ser humano deveria fazer o retorno ao Uno e fugir do mundo material.

Em sintonia com a visão de mundo quântica, na teoria de Plotino, ao estabelecer comércio com o mundo sensível, a alma perdeu sua origem plena, satisfeita, feliz e deve, portanto, iniciar o seu retorno para o reino espiritual. No entanto, a "caída" da alma é "um passo necessário para completar o reino intelectual" (SCOTT, 2014, p. 31). O uno é eterno e, como tal, nele não há limitação, ou seja, não há como identificar os seres. Nele tudo é; tudo é um eterno presente.

A experiência que o sujeito faz é a forma necessária de realizar a superabundância do mundo espiritual, ou seja, mundaniza a potencialidade do Uno, na teoria de Plotino; ou da Consciência Quântica, na visão de mundo quântica de Goswami. Na teoria da medição quântica de Goswami, o indivíduo não precisa sair do mundo para experienciar a unidade da Consciência Cósmica. Precisa reconhecer a natureza do ego e dos condicionamentos que o caracterizam; com isto, deve atentar-se ao insight ou intuição oriunda da modalidade quântica. Ao voltar a atenção para a modalidade quântica, para o self quântico, o indivíduo experiencia a unidade da Consciência sem sair do mundo.

Ao refletir sobre a ética idealista, Goswami questiona: "se a ética fosse um sistema fixo e racional de comportamento, de que maneira poderia ser detalhado o suficiente para abranger todas as situações e premissas em um mundo mutável?" (GOSWAMI, 2003, p. 306). Em vez de ser um sistema de padrões absolutos e rígidos, a Ética Quântica se alicerça na criatividade, pois é a partir dela que o indivíduo se abrirá às possibilidades de solução sempre que houver conflitos, dilemas ou ambiguidades. Goswami defende que "a ambiguidade gera criatividade, e esta é frequentemente essencial para encontrar soluções ótimas para dilemas" (GOSWAMI, 2003, p. 306).

O dilema ético surge a partir da dúvida e esta "ocorre porque não há solução lógica" para a situação (GOSWAMI, 2003, p. 306). Sendo assim, somente um salto quântico pode resolver o dilema. Goswami pontua que "quando a lógica é insuficiente 
para fornecer uma solução ética, ela só pode ser aplicada por um salto quântico criativo" (GOSWAMI, 2003, p. 306). O formalismo da ética quântica tem de postular como princípio geral a "preservação e a facilitação do acesso, ao nosso e do outro, à modalidade quântica" no nível intuitivo do ser, que inclua a liberdade e a criatividade (GOSWAMI, 2003, p. 306).

170 Goswami propõe três estágios para a prática da Ética Quântica: o primeiro estágio é denominado de "yoga ${ }^{5}$ da ação"; o segundo é a "yoga do amor" e o terceiro é a "yoga da sabedoria". No processo de desenvolvimento ético da pessoa, uma dessas yogas predomina, mas todas são praticadas simultaneamente (GOSWAMI, 2003, p. 308).

No estágio da "yoga da ação" o indivíduo "age sem apego aos frutos da ação" (GOSWAMI, 2003, p. 308). O objetivo da prática de não se apegar aos resultados da ação é perceber claramente os condicionamentos que operam nas decisões cotidianas, sejam as corriqueiras ou as mais ambíguas. Admitindo que na Consciência Quântica tudo é eterno, nada acontece no imanifestado, nela não existe a experiência (GOSWAMI, 2018, p. 136). E o ser humano só pode atingir seu propósito à medida que o vive na manifestação, na experiência, na ação. E a manifestação é mais efetiva quando não se apega aos frutos da ação.

Desta maneira, a ação boa é aquela realizada em vista da exploração do propósito arquetípico em consonância com a modalidade quântica que é criativa e livre. Por isto, é fundamental que que se identifique os atos condicionados para poder optar por agir moralmente (GOSWAMI, 2003, p. 308). A distinção entre self quântico e ego já foi destacada anteriormente. O que precisa agora ser acrescentado é que o ego não é algo que deve ser ignorado ou suprimido. Um ego forte é instrumento da Consciência para que a experiência possa ocorrer e, ainda mais, "ter alguém" para percebê-la. O self quântico é pleno, mas sua atuação no reino da unidade se dá em nível inconsciente. Se houvesse somente a unidade no nível do inconsciente, não haveria "alguém” para experienciar o que ocorre nesse domínio.

Se a pessoa se limitar aos seus circuitos cerebrais memorizados, nos padrões de comportamento, de sentimento ou de contextos de significados aprendidos e cristalizados; em outras palavras, se ficar somente nos condicionamentos que formam o ego, passa a ignorar todas as potencialidades e possibilidades da Consciência Quântica. Por outro lado, se ignorar o ego e todo o desfrute deste "eu" (ego) no mundo da manifestação, da felicidade, não haveria motivação para que a experiência fosse realizada qualitativamente. Dessa forma, a Ética Quântica requer uma dialética entre o self quântico e ego em busca da unidade fundamental. E a exploração do estágio da "yoga da ação" pode culminar na compreensão da unidade fundamental com o mundo, com a experiência intuitiva da criatividade interior (GOSWAMI, 2003, p. 308).

Na prática da "yoga da ação", o indivíduo pode disponibilizar o repertório do ego a serviço da manifestação do colapso da Consciência Quântica e ser uma pessoa criativa e livre por se estar atenta ao self quântico e aos condicionamentos que interferem nas tomadas de decisões. O método que pode auxiliar no processo criativo e integrativo dos self-ego, é o que Goswami chama de do-be-do-be-do (fazer-ser-fazerser-fazer), como visto acima.

Ao reconhecer a "yoga da ação" como um postulado prático da percepção consciente dos condicionamentos que influenciam nas decisões éticas da pessoa, seguese o outro que é o da "yoga do amor". Nesse estágio, o indivíduo age a serviço dos demais (GOSWAMI, 2003, p. 308). É o estágio do altruísmo no qual se descobre o "outro" e a validade das manifestações individuais dele. Agir a serviço dos demais inclui conservação da estrutura funcional e orgânica que garante a efetivação da experiência. A estrutura funcional e orgânica, em seu conjunto, pode ser denominada de vida, de pessoa ou de corpo com vida. Sem esta estrutura funcional e orgânica não há a manifestação da vida. A individualidade física do ser humano é tanto estrutural 
quanto funcional; além disto, existem as individualidades sutis que são as vitais e mentais que são funcionais (GOSWAMI, 2018, p. 109).

A vida é de difícil definição. No entanto, ao se considerar "as disposições naturais dum ser organizado, isto é, dum ser constituído em ordem a um fim que é a vida, aceita-se como princípio que nele se não encontra nenhum órgão que não seja o mais conveniente e adequado à finalidade a que se destina" (KANT, 2007, p. 24). A vida é a qualidade que expressa um ser organizado e orgânico.

Capra (2004, p. 135) entende que a os sistemas vivos têm três critérios totalmente interdependentes: o padrão, a estrutura e o processo. O padrão refere-se à forma, à ordem, à qualidade; a estrutura refere-se à substância química, matéria, quantidade (CAPRA, 2004, p. 33).

Segundo Capra, "o padrão de organização de qualquer sistema, vivo ou nãovivo, é a configuração de relações entre os componentes do sistema que determinam as características essenciais do sistema" (CAPRA, 2004, p. 134-135). O processo nos sistemas vivos "é a atividade envolvida na contínua incorporação do padrão de organização do sistema. Deste modo, o critério do processo é a ligação entre padrão e estrutura" (CAPRA, 2004, p. 134). No entanto, entende a vida como uma atividade emergente da complexidade elementar da matéria, como autopoiese ${ }^{6}$.

Um sistema ao modelo da autopoiese exibe três atributos inerentes e interdependentes: autolimitação, autogerador e autoperpetuador. Segundo Capra, em sua síntese sobre as teorias sistêmicas da vida, o ser autolimitado possui fronteiras que o distingue do seu meio ambiente; o ser autogerador significa que todos os componentes são produzidos por processos internos do sistema; e autoperpetuador significa que os processos acontecem ao longo do tempo de maneira que todos os componentes são repostos pelos processos de transformação (CAPRA, 2004, p. 169).

Um sistema autopoiético alcança em determinado momento a homeostase. O conceito de homeostase, entendido como "mecanismo auto-regulador que permite aos organismos manter-se num estado de equilíbrio dinâmico, com suas variáveis flutuando entre limites de tolerância", perpassa o entendimento de vida aceito por Capra (2004, p. 51). Além disto, a realimentação, conceito oriundo das realizações da Cibernética, perpassa a vida; sendo entendido como arranjo de comunicação na qual a "entrada" de informações ou estímulos é afetada pela "saída" de informações ou estímulos que "resulta na autorregulação de todo o sistema, uma vez que o efeito inicial é modificado a cada vez que viaja ao redor do ciclo" (CAPRA, 2004, p. 59).

Os conceitos de homeostase e de realimentação podem ser entendidos como mecanismos essenciais para que sistemas vivos se mantenham em equilíbrio dinâmico (CAPRA, 2004, p. 61). Contudo, esta concepção de vida não introduz a consciência como base do ser porque está teoricamente calcada em uma visão científica de vida como sendo um processo emergente das interações complexas e aleatórias das partículas e moléculas. No entanto, Goswami retoma as características sintetizadas por Capra (2004) e dá a elas um novo significado mediante a visão de mundo quântica e define o ser vivo como sendo:

um ser vivo consiste de aparatos de mensuração quântica em hierarquia entrelaçada, que são representações dos projetos vitais de funções biológicas, incluindo, mas não se limitando a, a manutenção e a reprodução. Tal ser é capaz de autorreferência porque, no processo do colapso quântico que a envolve, a consciência se identifica com o ser (GOSWAMI, 2009, p. 124).

A concepção capriana de vida não é negligenciada, mas sua validade é consequente, e não causal, porque ocorre somente depois de o colapso da função de ondas ser efetivado pela Consciência Quântica, conforme se depreende do excerto de Goswami sobre a definição de um ser vivo. Após o colapso da função de onda da possibilidade de o ser humano se manifestar, tem de se entender que a 
"autoconservação é um dever"7 (KANT, 2007, p. 27) para garantir que a Consciência Quântica atualize a pura potencialidade que encerra em sua unidade/totalidade. A cada colapso o self quântico se identifica com o cérebro, estrutura necessária que é simultaneamente colapsada pela Consciência Quântica.

Com o postulado prático da "yoga do amor", o ser humano se ocupa em agir a

172 serviço dos demais ${ }^{8}$. E a ação boa deve ser aquela que garanta a autoconservação de si e dos outros como condição para que, dinamicamente, ocorra mais colapsos descontínuos das ondas de possibilidade disponíveis no domínio da potencialidade pura. Sobre a "yoga do amor", Goswami escreve que "ouvimos o chamado do dever e atendemos. Servimos de maneiras diretas e imediatas para o bem de todos [...]" (GOSWAMI, 2003, p. 308).

Outro postulado prático da Ética Quântica é a "yoga da sabedoria” que consiste em agir "através de um alinhamento perfeito de nossa vontade com a vontade da modalidade quântica" (GOSWAMI, 2003, p. 308). A "nossa vontade" é caracterizada pelas decisões fundadas e influenciadas prioritariamente pelos condicionamentos que formam o ego. Deliberadamente é importante que o ego renuncie sua pretensão de domínio e que aja em prol da criação contínua de condições para colapsos futuros, expandindo o repertório disponível para eventos ainda não colapsados. Desta forma, a ação boa se caracteriza como aquela que otimiza e amplia as ondas de possibilidade.

Por meio da descrição do experimento da dupla fenda ficou evidente que uma onda de possibilidade quando cindida por outra onda de possibilidade, cria-se mais ondas de possibilidade. De modo análogo, à medida que uma pessoa trava contato e relações com outras pessoas ("yoga do amor"), criam-se novas ondas de possibilidade e se ampliam as ondas de possibilidade com o envolvimento do indivíduo na exploração das próprias potencialidades (integrando self quântico e ego).

Um indivíduo é uma onda de possibilidade que se expande ao explorar as potencialidades através de uma atitude arquetípica engajada, isto é, maximiza quando inclui em seu propósito a dimensão interpessoal. Nesta perspectiva, a democracia é um regime interpessoal que maximiza as potencialidades dos envolvidos ${ }^{9}$; a democracia pode ser entendia como a ocasião adequada para que os indivíduos se intencionem coletivamente e se correlacionem uns com os outros. Conforme a percepção consciente do tempo, dos significados e das ações vai-se expandindo para uma pessoa, as demais que estão correlacionadas a ela também sofrem, incialmente no inconsciente (não local), o colapso da função de onda semelhante.

Além disso, a teoria da medição quântica de Goswami prevê que a Consciência com percepção presente provoca o colapso da função de onda descontinuamente, embora, por causa dos condicionamentos, parece que há uma continuidade causal. $\mathrm{O}$ colapso é descontínuo, mas as ondas se expandem continuamente. Sendo isto uma propriedade intrínseca da Consciência, e a Consciência é o modo de perceber a experiência, é pertinente postular que à medida que uma experiência se dá, ela fíca registrada na memória e novas experiências, complementares, podem surgir para o sujeito.

A "novidade" é uma constante da experiência da vida. As chamadas crises acontecem como que um "alerta" para que os indivíduos humanos se deem conta de que o movimento cósmico da Consciência está se atualizando constante e criativamente a despeito de toda a força do ego contra o "novo contexto". A vida, tanto individual quanto coletivamente, tem de ser explorada, igualmente, pela criatividade. Por isto a Etica Quântica é a "ética da criatividade" e não do "comodismo". Para Goswami a concentração no momento e lugar "presentes" é uma condição para que o ser humano construa sua realidade a partir do self quântico, da modalidade quântica (GOSWAMI, 2018 , p. 108). Quando o indivíduo se concentra no "passado" (memória) ou no "futuro" (projeções) perde-se a capacidade de sentir a unidade subjacente do self quântico.

Com o postulado prático da "yoga da sabedoria", Goswami destaca que "ao 
renunciar ao ego em troca da modalidade quântica" o ser humano se realmente livre e criativo (GOSWAMI, 2003, p. 308) e se alinha vontade da Consciência unitiva. A vontade da consciência (tua vontade) e a "nossa vontade" não são coisas separadas. A "nossa vontade" deve ser entendida como a "vontade desde o ego" que, como foi justificado, é condicionado, não livre e não é criativo. Por outro lado, quando o indivíduo renuncia a agir "desde o ego" e de suas influências, e age a partir da modalidade quântica, do self quântico, que por sua vez é livre e criativo, segue a "tua vontade", a vontade da Consciência Quântica.

Quando a pessoa age desde o self quântico, segundo Goswami, a rigor a "ética e a moralidade não são mais necessários como guias porque não há mais qualquer conflito. Todos eles - ética, moralidade, conflito - dissolvem na vontade da consciência unitiva. Em seguida, há apenas a ação apropriada" (GOSWAMI, 308). Com a vivência dos postulados práticos da Ética Quântica, isto é, da "yoga da ação", da "yoga do amor" e da "yoga da sabedoria", o comportamento externo é moldado desde a criatividade interior, desde a alma. À medida que a transformação vai ocorrendo do nível do ego para o nível do self quântico, "a definição da boa vida como busca da felicidade muda gradualmente para uma vida de alegria" (GOSWAMI, 2003, p. 309).

\section{4.ÉTICA QUÂNTICA E PROPÓSITO}

Os critérios da Ética Quântica têm de passar pelo princípio geral da preservação e a facilitação do acesso, de si e do outro, à modalidade quântica no nível intuitivo do ser, que inclua a liberdade e a criatividade (GOSWAMI, 2003, p. 306). Para efetivar a Ética Quântica, tem-se os postulados práticos como o da "yoga da ação", da "yoga do amor" e da "yoga da sabedoria".

Da vivência destes postulados decorrem que: a) a experiência é necessária sem apego aos frutos; b) a experiência tem de garantir a autopreservação de si e dos outros, ou seja, é serviço aos demais, pois servir aos demais é servir a si mesmo por causa da unidade fundamental que a teoria quântica prevê conclusivamente segundo o experimento de Alain Aspect; c) a experiência tem de estar alinhada com a vontade da modalidade quântica e, consequentemente, as ondas de possibilidades para colapsos quânticos futuros são ampliadas.

À medida que as experiências são manifestadas, podem surgir perguntas sobre o conteúdo da Ética Quântica. Na visão quântica de mundo, a resposta é clara: os conteúdos são dados pelos arquétipos. Os arquétipos são objetos da experiência interior que proporcionam contextos para pensamentos e sentimentos intuitivos e criativos. A noção dos arquétipos foi desenvolvida primeiramente por Platão como sendo o mundo das Ideias e posteriormente usada por Jung para indicar as representações universais que fazem parte do inconsciente coletivo (GOSWAMI, 2018, p. 233).

Nesta linha de pensamento, os conteúdos advêm dos contextos arquetípicos que cada consciência individuada - cada pessoa - toma para si como propósito de explorar significados. Os principais contextos arquetípicos amplos são: o self, a bondade, $o$ amor, a inteireza, a verdade, a justiça, a beleza, a abundância e o poder. Estes contextos paradigmáticos se tornam infinitas possibilidades por causa das memórias que cada consciência individuada vai adquirindo ao longo da manifestação da vida e que tornam disponíveis como ondas de possibilidade na dinâmica da Consciência Quântica. Os arquétipos são os mesmos para todos, mas a representação que é efetivada deles pelos seres humanos depende essencialmente do repertório e habilidades desenvolvidas pelos indivíduos ao longo da vida. Por exemplo: uma pessoa muito habilidosa e com um repertório avantajado, ao se abrir à experiência do self quântico, consegue traduzir a intuição em manifestação com muito mais qualidade que aquele indivíduo que não domina as ferramentas necessárias para imprimir a ideia (arquétipo) 
no mundo material ou na dimensão manifestação.

Para explorar os significados arquetípicos tem de haver a dialética criativa do self-ego que pode ser realizada por meio do processo metodológico, caracterizada como do-be-do-be-do. Os conteúdos oriundos dos arquétipos platônicos são perfeitos e abundantes. Quem decide explorá-los passa pelo processo de crescimento e evolução ao compensar os circuitos cerebrais negativos com os circuitos cerebrais positivos.

\section{CONSIDERAÇÕES FINAIS}

Demos uma resposta filosófica ao problema sobre a possibilidade de uma ética quântica a partir do pensamento de Amit Goswami, apresentando a relação epistemológica entre "criatividade quântica e ética quântica"; "responsabilidade e ética quântica"; os "critérios universais de uma ética quântica"; por fim, a relação entre "ética quântica e propósito".

Apresentamos os critérios universais decorrentes da íntima relação entre consciência quântica e ética da responsabilidade diante do mundo e das pessoas a partir da analogia entre Goswami e Plotino. Partindo da concepção de homem como um ser animado por uma alma particular, Plotino desenvolveu sua teoria ética alinhada com a estrutura espiritual das hipóstases. $\mathrm{O}$ homem, em sua perfeição ética, deve empreender o retorno à sua origem, ao mundo espiritual por meio da renúncia ao comércio e à identificação com o mundo material ou mundo sensível.

Em Plotino os caminhos pelos quais o homem se eleva ao mundo espiritual são: as virtudes, a erótica e a dialética. Pela própria força interna, o homem ascende à dimensão cada vez mais elevada, isto é, ao mundo espiritual. Neste aspecto, constatouse que o homem deve fugir da relação com o mundo sensível à medida que experienciar, por meio do êxtase, a iluminação. A Ética Quântica, na perspectiva de Goswami, parte da concepção de homem como o self quântico que é resultado da hierarquia entrelaçada, provocada pela causação descendente, na qual a consciência quântica se identifica com o sujeito (self) ao observar o objeto. O homem é uma individuação da Consciência Quântica manifestada que se identifica com o sujeito, com o self. A percepção de que o ser humano é separado da consciência quântica, surge por meio das chamadas assinaturas quânticas e pelos condicionamentos retroalimentados que formam o "ego".

Uma característica fundamental da ética quântica é a criatividade. Esta característica está em consonância com a visão quântica, cujos princípios são: princípios da incerteza, da complementaridade, da descontinuidade, da inseparabilidade, do observador consciente e da não-localidade.

Fazendo a relação da criatividade ética com os elencados princípios da teoria quântica, destacamos que do princípio da incerteza se pode extrair o entendimento de que o desejo de domínio sobre os indivíduos, ou até mesmo sobre o ambiente à volta desses, não se justifica. Assim, a criatividade é compatível com o princípio da incerteza. A criatividade ética se adequa ao princípio da complementaridade. O self quântico é complementado pelo self condicionado. O self quântico oferece a intuição e o ego, alicerçado nas habilidades aprendidas e armazenadas no repertório "pessoal", se encarrega de dar "concretude" à intuição ou insight. Goswami, nesse aspecto, afirma que a criatividade interior não se torna completa até que o "produto", a transformação do self, seja "concluída e comunicada para que os outros vejam" (GOSWAMI, 2003, p. 307).

A criatividade ética não é um sistema rígido, inflexível, de comportamento ou até mesmo de regras, por isso é compatível com o princípio da descontinuidade, da inseparabilidade e com os demais princípios da teoria quântica. A criatividade ética, como característica essencial da ética quântica, revela uma perspectiva de plena 
abertura do observador ao momento presente, sempre à espreita do movimento e da expansão da consciência. A criatividade é o domínio da liberdade. Desta forma, a criatividade quântica é o método para solucionar dilemas e paradoxos que afligem as relações humanas. E por ser criativo e livre, o ser humano também é responsável. A responsabilidade se impõe como exigência pelo princípio da inseparabilidade.

A ética quântica, segundo Goswami tem de refletir sobre a busca da felicidade pelo homem (GOSWAMI, 2003, p. 298) e, nessa perspectiva, tem de orientar para um movimento na direção da totalidade, para a integração do self quântico e self-ego (GOSWAMI, 2003, p. 298). A ética quântica tem de explorar o "bem" entendido como a vivência do indivíduo a partir da modalidade quântica enquanto se está no mundo. A partir disto, a ética quântica tem de postular como princípio geral a "preservação e a facilitação do acesso, ao nosso e do outro, à modalidade quântica" no nível intuitivo do ser, que inclua a liberdade, a criatividade e a responsabilidade (GOSWAMI, 2003, p. 306).

Goswami propõe três estágios que se interpenetram enquanto se explora a ética quântica, a saber: agir sem apego aos frutos da ação; agir a serviço dos demais; agir alinhado à vontade da modalidade quântica.

Evidenciamos que ao expandir consciência de uma pessoa, ela possa fazer escolhas com originalidade a partir de um nível inviolado, que é a consciência quântica, tornando-se criativa e responsável; o processo de descoberta da autoconsciência como desdobramento autorreferencial da Consciência, se aplicado à educação, tem impacto direto nas relações entre as pessoas visto que podem se descobrir como co-criadores da realidade porque se percebem como observadores conscientes com autorreferência, como sujeitos que escolhendo com criatividade podem transformar o mundo enquanto se transformam.

\section{REFERÊNCIAS}

ARISTÓTELES. Ética a Nicômaco. 4. ed. São Paulo: Nova Cultural, 1991.

CAPRA, Fritjof. O tao da física: um paralelo entre a física moderna e o misticismo oriental. São Paulo: Cultrix, 1983.

GOSWAMI, Amit. O Universo autoconsciente: como a consciência cria o mundo material. Rio de Janeiro: Rosa dos Tempos, 2003.

GOSWAMI, Amit. A fisica da alma. São Paulo: Aleph, 2005.

GOSWAMI, Amit. O médico quântico: orientações de um físico para a saúde e a cura. São Paulo: Aleph, 2006.

GOSWAMI, Amit. Deus não está morto: evidências científicas da existência divina. 2. ed. São Paulo: Goya, 2015.

GOSWAMI, Amit. A janela visionária: um guia para a iluminação por um físico quântico. 12. ed. São Paulo: Cultrix, 2013.

GOSWAMI, Amit. Evolução criativa das espécies: uma resposta da nova ciência para as limitações da teoria de Darwin. São Paulo: Aleph, 2009.

GOSWAMI, Amit. Economia da consciência: o poder da economia da consciência. São Paulo: Goya, 2015.

GOSWAMI, Amit. Criatividade para o século XXI: uma visão quântica para a expansão do potencial criativo. 2. ed. São Paulo: Goya, 2015.

GOSWAMI, Amit. Consciência quântica: uma nova visão sobre o amor, a morte e o sentido da vida. São Paulo: Aleph, 2018.

JUNG, Carl Gustav. Os arquétipos e o inconsciente coletivo. 11. ed. Petrópolis: Vozes, 2014.

KANT, Immanuel. Fundamentação da metafísica dos costumes. Lisboa: Edições 70, 2007.

MARTINS, Paulo Nuno Torrão Pinto. A mecânica quântica e o pensamento de Amit Goswami. 2009. Tese (Doutorado em História e Filosofia das Ciências) - Universidade Nova de Lisboa - Faculdade de Ciências e Tecnologias, Lisboa - Portugal. 
PLATÃO. A república. Tradução de Carlos Alberto Nunes. 3. ed. Belém: EDUFPA, 2000.

PLOTINO. Primeira enéada. Tradução José Rodrigues Seabra Filho e Juvino Alves Maia Junior. Belo Horizonte: Nova Acrópole, 2014.

PLOTINO. Segunda enéada. Tradução José Rodrigues Seabra Filho e Juvino Alves Maia Junior. Belo Horizonte: Nova Acrópole, 2015.

176 PLOTINO. Quarta enéada. Tradução José Rodrigues Seabra Filho e Juvino Alves Maia Junior. Belo Horizonte: Nova Acrópole, 2017.

PLOTINO. Quinta enéada. Tradução José Rodrigues Seabra Filho e Juvino Alves Maia Junior. Belo Horizonte: Nova Acrópole, 2018.

PLOTINO. Enneadi. Milano: Bompiani, 2018.

SCOTT, Julian. A doutrina da alma nas Enéadas. In: PLOTINO. Primeira enéada. Tradução Rodrigues Seabra Filho e Juvino Alves Maia Junior. Belo Horizonte: Nova Acrópole, 2014.

SEABRA FILHO, José Rodrigues; MAIA JUNIOR, Juvino Alves. Introdução. In: PLOTINO. Primeira enéada. Belo Horizonte: Nova Acrópole, 2014.

\section{Notas}

1 A ética de Aristóteles tem por telos da ação humana a felicidade: "verbalmente, quase todos estão de acordo, pois tanto o vulgo como os homens de cultura superior dizem ser esse fim a felicidade e identificam o bem viver e o bem agir como o ser feliz" (ARISTÓTELES, 1991, p. 8).

2 Sincronicidade é um conceito usado por Jung entendido como "um princípio de conexões acausais" (JUNG, 2014, p. 28).

3 Refere-se ao experimento de Jacobo Grinberg e colaboradores que já foi replicado por outros cientistas de outras maneiras com resultados similares aos obtidos por Grinberg e colaboradores.

4 Ao modo de imperativo categórico kantiano.

5 De acordo com Martins, yoga é um “termo sânscrito que significa 'união' ou 'controle das modificações da mente"” (MARTINS, 2009, p. XIV).

6 Com o termo autopoiese quer indicar a capacidade próprias dos sistemas vivos se organizarem em uma organização circular e, portanto, constante. “Auto significa 'si mesmo' e se refere a autonomia dos sistemas auto-organizadores, e poiese - compartilha a raiz grega com a palavra grega 'poesia' - significa 'criação', 'construção'. Portanto, autopoiese significa "autocriação"” (CAPRA, 2004, p. 88).

7 “Conservar cada qual a sua vida é um dever, e é além disso uma coisa para que toda a gente tem inclinação imediata. [...]. Os homens conservam a sua vida conforme ao dever, sem dúvida, mas não por dever" (KANT, 2007, p. 27).

8 Tem de manter em mente a unidade fundamental conforme concluiu Alain Aspect.

9 Vale destacar que a democracia deve ser levada a sério, pois a realidade é uma construção mediante a percepção de cada pessoa. O aspecto aparente da democracia de inclusão dos outros na esfera das tomadas de decisões ou nas discussões de uma temática é prejudicial porque as pessoas não se percebem como protagonistas da experiência e essa aparente participação pode criar um ego fraco apegado a experiências medíocres nas quais tiveram "êxitos" superficiais. A democracia aparente impede que as pessoas se potencializem e explorem o que há de melhor em si. 